\title{
Repositioning Urban Heritage-Setting the Scene
}

\author{
Michael Turner \\ Graduate Program in Urban Design, Bezalel Academy of Arts and Design, Jerusalem, Israel \\ Email: unescochair@bezalel.ac.il
}

\begin{abstract}
International conventions, charters and recommendations tend to follow trends and are generally reactive to contemporary circumstances; the debates on urban heritage are no exception. These texts need to be read in the perspective of socio-economic and environmental considerations of their time together with their interdependence on other disciplines. The dramatic changes to our urban conurbations have included environmental degradation, the complexities of migrations and socio-economic transformations. Addressing these major concerns in managing urban heritage highlights the necessity for cross-disciplinarity in research and the need for adopting a more integrative attitude in the planning processes. Applying the General System Theory by the biologist Ludwig von Bertalanffy brings a systematic, holistic methodology from the realms of modern science into extending the historic centre and the city with a territorial approach of the metropolis allowing for sustainable and resilient rural and urban linkages. This article brings together seven contributions on issues affecting the Recommendation on the Historic Urban Landscape The potential of the digital revolution is in the capacity of recognizing the speed and rapidity of change, and the mega-data available as affecting our lives and environment together with the role of history, tradition and continuity in linking the past to the future.
\end{abstract}

KEYWORDS urban heritage, general system theory, integrative planning, Historic Urban Landscape, New Urban Agenda

International conventions, charters and recommendations tend to follow trends and are generally reactive to contemporary circumstances; the debates on urban heritage are no exception. These texts need to be read in the perspective of socio-economic and environmental considerations of their time together with their inter-dependence on other disciplines. Our story starts with the rebuilding of cities after the WWII in Europe and East Asia thereby becoming living laboratories for the challenges in the new social and political orders.

The establishment of UNESCO was a direct consequence of 'the great and terrible war' and which was 'made possible by the denial of the democratic principles of the dignity, equality and mutual respect of men', with its purpose in achieving peace by giving fresh impulse to popular education and to the spread of culture. This would be realised, inter alia, 'by assuring the conservation and protection of the world's inheritance of books, works of art and monuments of history and science, and recommending to the nations concerned the necessary international conventions.'

The recognition of urban heritage as an integral component part of the city has been slow in coming. The first years after WWII were characterised by viewing the urban fabric as a defined area, considered as an extension of the setting and context of the monuments, sites or architectural components of parts of the city. The French Malraux Act in 1962 introduced secteurs sauvegardés within which historic fabric was not only protected but also enhanced (Kain and Phillips 1978). Then the four UK demonstration conservation studies for Chichester, York, Bath and Chester prepared in the 1960s were a mind-set change in the throes of the post-war redevelopment and concepts of a brave new world structured in the Civic Amenities Act 1967 (Pendlebury and Strange 2011). In contrast, mainland Europe, based on ideological impetus, had led a series of reconstructions, from Warsaw to Le Havre, well recognised in the publications of the European Heritage Year of 1975. In East Asia, from Nagasaki to Manila, this 


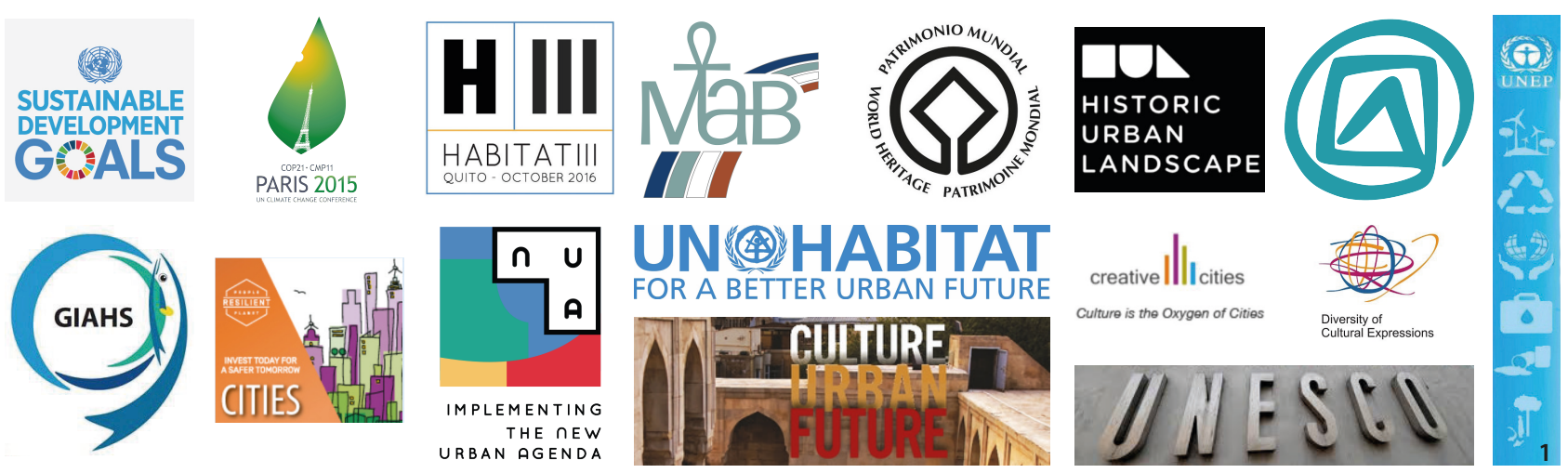

Figure 1 The transformative power of urbanisation (Source: the author).

was seen as an opportunity to build anew.

In its debate on the Recommendation Concerning the Safeguarding and Contemporary Role of Historic Areas, 26 November 1976, the General Conference meeting in Nairobi noted the 'absence in many cases of a legislation effective and flexible enough concerning the architectural heritage and its interconnexion with town-planning, territorial, regional or local planning' (UNESCO 1976). The decision recalled that during the past two decades, over and above the Convention for the Safeguarding of the World's Cultural and Natural Heritage, 1972, it had already 'adopted international instruments for the protection of the cultural and natural heritage such as the Recommendation on International Principles Applicable to Archaeological Excavations (1956), the Recommendation Concerning the Safeguarding of the Beauty and Character of Landscapes and Sites (1962), the Recommendation Concerning the Preservation of Cultural Property Endangered by Public or Private Works (1968), and the Recommendation Concerning the Protection, at National Level, of the Cultural and Natural Heritage (1972).

Subsequently, the ICOMOS Charter for the Conservation of Historic Towns and Urban Areas, (Washington Charter 1987) was approved as it was 'necessary to draw up an international charter for historic towns and urban areas that will complement the International Charter for the Conservation and Restoration of Monuments and Sites, usually referred to as the Venice Charter.' Since then, together with the 1994 Nara Document (ICOMOS 1994), there have been many conferring documents adopted in the ICOMOS family, where the monument and site became the object of further dialogue with their surroundings being its context and setting, notably in 2005 with the Xian Declaration on the Conservation of the Setting of Heritage Structures, Sites and Areas and the 2008 Québec Declaration on the Preservation of the Spirit of
Place. Even so, there was a reluctance in these documents to recognise the presence of urban heritage per se.

The World Heritage Committee at the outset of the millennium, in debating the growing threats to properties in an urban setting, became a barometer for the effects of global urbanisation, generating the 2005 Vienna Memorandum concerning 'World Heritage and Contemporary Architecture-Managing the Historic Urban Landscape'. Urban Heritage at UNESCO finally came into its own in 2011 with the approval of the Recommendation on the Historic Urban Landscape (UNESCO 2011). This was after a six-year global debate which responded to interventions made by professional bodies and international institutions beyond the pale. This volume has been triggered by the reflections on the Recommendations of the Historic Urban Landscapes and the many reactions and studies that have appeared in books, articles and references around the world.

Over the past decades, the world has experienced dramatic changes which have included addressing environmental degradation, the complexities of migrations, socio-economic transformations and currently, the potentials of the digital revolution. These issues have been addressed globally by further texts, documents and declarations, especially the 1972 Stockholm Conference, the 2015 UN Sustainable Development Goals, the 2016 UNHabitat New Urban Agenda, the UNISDR Resilient Cities Programme and the Climate Change Framework. Human rights, personal responsibilities and public engagement are also compounded with silo-structured entities and actions (Figure 1).

How have these mechanisms tackled urbanisation? Has the adoption of an agenda addressing culture for sustainable development been successful? What has been missing in their effectiveness to support urban heritage and the vitalisation of our cities? 
Cultural heritage in the World Heritage Convention of 1972 was defined as 'monuments', 'groups of buildings' and 'sites', with urban heritage referenced by ICOMOS as 'groups of buildings'. While a city may, indeed, be defined as a group of buildings, it does not provide for the attributes of the very essence of the city, its streets and boulevards, the piazzas and courtyards, its human fabric including the tangible and intangible assets, its natural and cultural features and all that constitutes the heart and soul of the city. The array of articles in this volume expands on these component parts adding new dimensions to understanding the historic, the urban and the landscape. This could be paralleled with their human relationships; the historic between human and ancestors, the urban between human and human and the landscape between human and nature.

Allow me to set the scene highlighting three of the major concerns that we will face in the coming decade. The first is clearly the speed and rapidity of change, and the mega-data available as affecting our lives and environment within the digital age. This was expressed in Moore's Law, adapted since 1975, determining that the number of transistors on a chip, managing data, doubles every two years. The second is a panacea to the first that links the past to the future being the role of history, tradition and continuity. The third concern highlights the necessity for cross-disciplinarity in research and the need for adopting a more integrative approach within the international agendas of environment and climate, nature and culture, tangible and intangible. These concerns all need to be addressed through the considerations of sustainability and resilience of the city at all shapes and sizes from the smallest human settlement to the emerging metropolises of the world, thus ensuring longevity for urban heritage.

The UNESCO Category 2 Centre, World Heritage Institute of Training and Research for the Asia and Pacific Region, held an international expert meeting on the implementation of the Historic Urban Landscape Recommendation in Shanghai, China, March 2018. In debating the principles and good practices of the Recommendation, the experts addressed varied urban scales, from small settlements to the metropolis, the varied urban typologies, from walled cities to modern heritage, and the links between urban setting, nature, climate change and the intangible. They finally looked to the future, and beyond the case-studies that were presented addressing the relevance for the UN-Habitat New Urban Agenda in a more holistic manner. In this special issue seven of the participants come together and reflect on the current state of the Recommendation on the Historic Urban Landscape and offer insights as to its application, relevance and future.

It is this holistic approach which engages the diverse urban disciplines and to which the 2011 Recommendation on the Historic Urban Landscape is applied in the urban context. This was highlight by Francesco Siravo (Bandarin and van Oers 2014, 161-175) in his comment that the $19^{\text {th }}$ century concept of restoration was being applied to urban ensembles, noting the examples of Carcassonne in the 1850 s and Split in the 1900s. Such an approach cannot be considered without applying some theory or methodology, and I commend the General System Theory by the biologist Ludwig von Bertalanffy that brings the holistic approach into the realms of modern science. 'We may state as characteristic of modern science that this scheme of isolable units acting in one-way causality has proved to be insufficient. Hence the appearance, in all fields of science, of notions like wholeness, holistic, organismic, gestalt, etc., which all signify that, in the last resort, we must think in terms of systems of elements in mutual interaction.' (Von Bertalanffy 1968, 45). The Historic Urban Landscape approach inherently builds on these notions through the significance of the all-encompassing attributes of the city. The articles in this special issue evaluate the relevance of the approach, picking the strengths and weaknesses.

Landscape is part of our collective perception responding to the importance of natural and cultural diversities and their mutual interdependencies. To underscore this, Ken Taylor introduces the Cultural Landscape Model perceived as a cultural construct reflecting human values (Bandarin and van Oers 2014, 179-202). It is not surprising that the first article by Maya Ishizawa looks at the nature culture linkages in Asia where the Nara Document (ICOMOS 1994) was nurtured. Historically, the natural sciences have always preceded the humanities, scientifically managing human interventions and with detailed measurements and empiric analyses. The Japanese do not have the need to generate these linkages as they are inherent in their way of life-satoyama and satoumi are the cultural landscapes where Shinto beliefs and traditional agricultural practices knit together, while the defining of 'nature' and 'culture' renders the divide inadequate. Living and livelihood are part and parcel of understanding these linkages which are a far cry from the Western cultural landscapes visually highlighted by French and English traditions. Maya also notes some more relevant mechanisms as the Food and Agriculture Organisation's initiative on Globally Important Agricultural Heritage Systems, a subject that will surely appear high on the agenda in the coming years. Adding to this, the urban biospheres 
may provide yet another appropriate mechanism that can engage the peri-urban spaces of the city and give function to these liminal spaces as part of the policies for urbanrural linkages in the New Urban Agenda (Habitat III Secretariat, 2017).

These Shinto beliefs more pantheistic than animistic embrace the kami as shrine practice investing 'in mountains, trees, rocks, and other natural phenomena a sacred quality and identifies them as the dwelling places of the kami deities. These facts point to a defining relationship between Shinto and nature' (Breen and Teeuwen 2013, 2). Similarly, these holistic concepts with the attributes of nature are echoed in the thoughts of Spinoza. Stuart Hampshire in expounding these thoughts notes that to 'say that God is the immanent cause of all things is another way of saying that everything must be explained as belonging to a single and all-inclusive system which is Nature' (Hampshire 1951, 44).

The application of the Historic Urban Landscape Approach at different scales is the acid test as to its usefulness and validity within the urban context of human settlement. This is all the more critical in applying target 11.4 to Goal 11 of the UN Sustainable Development Goals 'safeguard[-ing] the world's cultural and natural heritage' in order 'to make our cities and human settlements safe, inclusive, resilient and sustainable.' Defining the metropolis challenges the accepted urban-rural linkages of the New Urban Agenda. The sustainability and resilience of the city requires a re-describing of the relevant boundaries in determining its functionality to be safe and inclusive. Max Weber in characterising the nature of the city looks towards economic sustainability in the relationships between the city and its agriculture (Weber 1958). The city expanding reduces the rural liminal spaces to the role of environs, and the surrounding villages experience the evolution of synoecism (Vance 1990, 73-75). Eric Huybrechts provides a position paper looking at the metropolis, noting that some 50 cities currently have over 10 million inhabitants and with half the urban population living in metropolitan areas it will become the main artefact of the $21^{\text {st }}$ century. He redefines the city and evokes the need for territorial planning which was initiated in the 1990s in the ICCROM Territorial Studies initiative that was led by the late Herb Stovel and Joe King, the current director of the cities programme. It was with the growing urbanisation of this period that brought about a new realisation as to the threats on the Outstanding Universal Value of the properties inscribed in an urban setting. Eric underlines the links that integrate the different communities, identities, sectors and territories that need to be taken into account in developing the role that the Historic Urban Landscape approach could adopt in identifying the heritage characteristics of the metropolis. Considering the growth of our urban fabric we need perhaps need to adopt a definition of the 'multitude' as developed by Spinoza rather than 'diversity'. It is a term for a group of people who cannot be classed under any other distinct category except for the shared fact of their existence, being an essential definition of those living in the mercurial metropolis, swiftly moving and reshaping itself. Antonio Negri and Michael Hardt adopt this term and apply this to the modern city with its neo-liberal baggage (Negri and Hardt 2004). However, they have been critiqued with the misinterpretation of Spinoza, but that only goes to show the resilience of the Spinozan texts and their creative ambiguity.

China is way ahead of the world in applying technology in the city, not just for efficient infrastructure but also in our day-to-day activities-a double-edged sword. China has begun preparing programs and cities for an autonomous driving revolution expected to generate $\$ 1$ trillion in revenue globally, the South China Morning Post reported. Nearly 300 Chinese cities and regions, including Xinjiang and Nanjing, have already introduced 'smart-city' projects controlled by artificial intelligence technology to enhance daily life. Smart cities use cloud-based technology to integrate across several industries, including transportation, health care and public security, according to governmentowned China Daily. Xi Wang has applied crowd sourcing to elicit information as to how citizens perceive the city and their experiences supported by space syntax methodologies to comprehend the urban complexities. The digital innovative framework in the Chinese context for the Historic Urban Landscape was developed based on the combined understanding of landscape value orientation and the digital heritage progression trend, with categories consisting of multiple information types generated by integration technics. The virtual network allows us to imagine a platform, where people are able to access and participate in the process of the implementation of the Historic Urban Landscape approach with the system constantly evolving with the impact of real time urban data.

The buildings of today will be the heritage of tomorrow and therefore our understanding of the developments that took place in the $20^{\text {th }}$ century when we moved from the avant-garde Futurists of the first decades to the digital seers and clairvoyants of the last decades requires a new understanding that has been researched globally by Edward Denison. His contribution on modern heritage in Asia and 
Africa reflects his knowledge and personal involvement in the heritage of Manchuria and Eritrea and the intelligent application of the Recommendation on the Historic Urban Landscape that may assist us in integrating this epoch into our cities. He challenges the euro-centricity of the heritage movement noting that of the ' 23 signatories responsible for drafting the International Charter for the Conservation and Restoration of Monuments, 21 were male, 19 were European, three were American, and one was from North Africa (Tunisia). None were from Asia, Oceania or SubSaharan Africa.' Much time is spent in translating English or French nomenclature into vernacular languages and the meanings of landscape in the Chinese context are better summed up in the term shanshui (mountain-water). Shanshui landscape painting evokes the spirits of the mountains and the poetry of the place integrating brush and ink techniques with calligraphy. It was holistic in its representation and often embodied urban scenes, processions, rituals and events. These principles were extended to landscape design implying a deep respect for natural forces, while allowing nature to shape the garden. We should adopt the term Historic Urban Shanshui.

At the outset of this century, the timing of the Intangible Cultural Heritage Convention in 2003 together with the recognition of cultural diversities in 2005 was a major change of outlook, and Harriet Deacon expands on the different understandings of the intangible concept. Julian Smith in the 2006 University of Montreal Round Table had said that 'urban heritage needs to encompass the historic environment as a space for ritual and human experience' (Cameron, 2006). While the issues of cultural diversity are highlighted in the Nara Document, the Burra Charter and lately the 2005 UNESCO Convention on the Protection and Promotion of the Diversity of Cultural Expressions, Harriet challenges the need to better integrate the intangible values, and that more needs to be done in the application of the Recommendation. People and communities are at the heart of the World Heritage convention with Article 5 ensuring that effective and active measures are taken '(a) to adopt a general policy which aims to give the cultural and natural heritage a function in the life of the community and to integrate the protection of that heritage into comprehensive planning programmes. These are points well taken and should provide a warning signal in the continuing application of the approach.

Managing the urban values under the contemporary urban threats as identified by the World Heritage Centre in its analysis of the State of Conservation reporting has been a challenge. The Heritage Impact Assessment emerged but was guided by the architectural preservators as opposed to the urban conservators. Impact assessment has come a long way since its emergence in the fields of environment-the very nexus of culture and nature and the basis for the Recommendation. Here Dennis Rodwell and I lead an evaluation of the relevance of the Heritage Impact Assessment and how it may be better applied within the urban context. The Environmental Impact Assessment of the late 1960s has been augmented with, inter alia, Risk Assessment, Health Impact Assessment, Heritage Impact Assessment and Socio-economic Impacts. Yet again, a more holistic approach is vital in evaluating the threats and in taking the opportunities that the city provides by developing a proactive-Strategic (Environmental) Assessment being a landscape scale together, where necessary, a reactive-Integrated Impact Assessment as the 'process of identifying the future consequences of a current or proposed action' as defined by the International Association for Impact Assessment.

The 'way forward' concludes the special issue, and where Yonca Erkan has underscored the need to engage other international mechanisms, develop case studies, and be creative and innovative in the application of the approach. The UNESCO Recommendation on the Historic Urban Landscape is being carefully monitored so as to understand its application in the urban scene. It was conceived as an approach rather than a category so as not to be confused with Cultural Landscapes. However, terminology will have its own life and the term is becoming part and parcel of the urban lexicon, although this will require further discussion in the consideration of the city as a distinct category rather than the current accepted usage of the World Heritage committee: 'group of buildings'. Here, Yonca who has been coordinating the 2019 reporting exercise for the Recommendation provides some concluding thoughts. She associates the terminology with the Historic representing the layers, old and new, the Urban being the tangible and intangible heritage, the Landscape represented by the symbiosis of nature and culture and the Approach being the Management of the whole including community involvement and partnerships.

Already in 2006, the Montreal Round Table, underscored that misunderstandings exist over the relationship of the term 'historic urban landscape' to other World Heritage definitions like 'cultural landscape, 'urban ensemble' and 'heritage landscape' and an urban taxonomy is urgently required (Cameron 2006). Focusing on this new taxonomy will be the need for defining of the remnants of the urban past, together with urban areas and 
fragments within the diverse urban forms of the cities from time immemorial.

The dichotomy between urban heritage and development needs to be resolved through the Historic Urban Landscape approach adopted in 2011 by UNESCO which set 'culture as an enabler for sustainable development' (UNESCO Culture Sector 2018). However, with the multiplicity of documents between 2011 and 2016, there is a confusion in their implementation and a need to harmonise these directives while engaging new digital technologies as prioritised by the UN Secretary-General in his inaugurating speech in July 2018 at the High-level Panel on Digital Cooperation. He made clear that 'digital technology is changing economies and societies at warp speed. The scale and pace of change is unprecedented, but the current means and levels of international cooperation are unequal to the challenge and technology is not standing still; developments are accelerating. This special issue has brought together component parts of our urban heritage to promote the city of the future while engaging digital technologies as key to identity and continuity for the multitudes.

\section{References}

Bandarin, Francesco, and Ron van Oers, eds. 2014. Reconnecting the City: The Historic Urban Landscape Approach and the Future of Urban Heritage. Chichester: Wiley Blackwell.

Breen, John, and Mark Teeuwen, eds. 2013. Shinto in History: Ways of the Kami. London: Routledge.

Cameron, Christina, ed. 2006. Heritage and the Conservation of Historic Urban Landscapes. Montreal: University of Montreal. http://whc.unesco.org/uploads/activities/documents/activity-47-4.pdf

Habitat III Secretariat. 2017. New Urban Agenda. New York: United Nations.

Hampshire, Stuart. 1951. Spinoza. New York: Penguin Books Ltd.

ICOMOS. 1994. Nara Document on Authenticity. Nara: ICOMOS. https://www.icomos.org/charters/nara-e.pdf

Kain, Roger, and Peggy A. Phillips. 1978. "Conservation Planning in France: Poliocy and Practice in the Marais, Paris." Urbanism Past \& Present 7: 22-34.

Negri, Antonio, and Michael Hardt. 2004. Multitude: War and Democracy in the Age of Empire. New York: The Penguin Press.

Pendlebury, John, and Ian Strange. 2011. "Centenary Paper: Urban Conservation and the Shaping of the English City." Town Planning Review 82 (4): 361-392.
UNESCO Culture Sector. 2018. Culture for the 2030 Agenda. Paris: UNESCO.

UNESCO. 1976. "Recommendation Concerning the Safeguarding and Contemporary Role of Historic Areas." Accessed 24 December 2018. http://portal.unesco. org/en/ev.php-URL_ID=13133\&URL_DO=DO_ TOPIC\&URL_SECTION=201.html

UNESCO. 2011. "Recommendation on the Historic Urban Landscape.” Accessed 24 December 2018. http://portal. unesco.org/en/ev.php-URL_ID $=48857 \% 26 \mathrm{URL}_{\text {_ }}$ DO=DO_TOPIC\%26URL_SECTION=201.html

Vance, James E, Jr. 1990. The Continuing City: Urban Morphology in Western Civilization. Baltimore: The Johns Hopkins University Press.

Von Bertalanffy, Ludwig. 1968. General System Theory: Foundations, Development, Applications. New York: G. Braziller.

Weber, Max. 1958. The City. Edited by D. Martindale and G. Neuwirth. Translated by D. Martindale and G. Neuwirth. Glencoe: The Free Press. 